\title{
The effects of a low-sodium base-producing diet including red meat compared with a high-carbohydrate, low-fat diet on bone turnover markers in women aged 45-75 years
}

\author{
Caryl A. Nowson*, Annabelle Patchett and Naiyana Wattanapenpaiboon \\ School of Exercise and Nutrition Sciences, Centre for Physical Activity and Nutrition Research, Deakin University, \\ 221 Burwood Highway, Burwood 3125, Victoria, Australia \\ (Received 6 May 2008 - Revised 3 April 2009 - Accepted 6 April 2009 - First published online 18 May 2009)
}

A randomised, parallel-design dietary intervention study was conducted in women (aged 45-75 years) with prehypertension or stage 1 hypertension. The aim was to compare the effects on bone turnover of a low-Na base-producing (LNAB) Dietary Approaches to Stop Hypertension (DASH)-type diet (including six serves lean red meat/week) with a high-carbohydrate low-fat (HCLF) diet with a higher acid load (both $>800 \mathrm{mg}$ dietary $\mathrm{Ca} / \mathrm{d}$ ). Fasting serum bone markers (baseline and week 14 ) and $24 \mathrm{~h}$ urinary electrolyte excretion (baseline, weeks 4, 8, 12 and 14) were measured. After the intervention period, the LNAB group $(n$ 46) had a fall of 26 (SEM 6) \% $(P<0.0001)$ in urinary Na, an increase in K excretion (6.8 (SEM 3.6) $\mathrm{mmol} / \mathrm{d} ; P=0.07)$ and, compared with the HCLF group ( $n$ 49), a greater reduction in urinary Ca excretion by $0.7($ SEM 0.3$) \mathrm{mmol} / \mathrm{d}$. Serum 25 -hydroxyvitamin $\mathrm{D}$, intact parathyroid hormone and osteocalcin did not change, and both groups had a similar increase of 23 (SEM 5) \% $(P<0 \cdot 0001)$ in C-terminal telopeptide of type I collagen. The HCLF group had an $11($ SEM 4$) \%$ increase $(P=0 \cdot 003)$ in $\mathrm{N}$-terminal propeptide, type I procollagen, which could indicate an increased rate of bone turnover. The fall in urinary Ca with the lower-Na loweracid load diet is likely to have long-term beneficial effects on bone. As bone resorption was not different between the two dietary patterns with relatively high $\mathrm{Ca}$ intake, the effect on bone health of a dietary pattern with a lower acid load warrants further study on a lower Ca intake.

Dietary interventions: Dietary Approaches to Stop Hypertension (DASH) diet: Osteoporosis: Sodium: Bone turnover

Dietary patterns are increasingly being recognised as having an important role in the maintenance of bone health. For example, diets rich in $\mathrm{Ca}$ have been found to reduce bone loss ${ }^{(1)}$ and reduce fracture ${ }^{(2)}$. It has been proposed that the body's acid-base environment has an impact on bone health and is also modifiable by diet ${ }^{(3-5)}$ where a higher dietary acid load contributes to bone loss. In industrialised countries diets tend to be high in carbohydrates and low in fruit and vegetables, and this, coupled with higher intakes of protein from animal sources, results in a high dietary acid load, which is proposed to contribute to a decrease in blood $\mathrm{pH}$ via the increased production of hydrogen ions ${ }^{(3)}$. It has been estimated that for a pre-agricultural diet consisting of $35 \%$ meat and $65 \%$ plant foods, the net endogenous acid production (NEAP) yields a negative NEAP value. This is in contrast to our current Western diet with a positive NEAP value. The shift from negative to positive NEAP is accounted for by the displacement of high-bicarbonate-yielding plant foods in the ancestral diet by cereal grains resulting in a net acid-producing $\operatorname{diet}^{(3)}$. While the body possesses multiple mechanisms for maintaining a suitable acid-base environment, it has been suggested that prolonged acidosis contributes to a decrease in bone density via the activation of osteoclastic $\mathrm{Ca}$ mobilisation and an associated inhibition of bone mineralisation.

Several cross-sectional studies in older adults have examined the effect of a diet high in fruit and vegetables on bone mineral density $(\mathrm{BMD})^{(6-8)}$, and the results indicate that dietary patterns high in fruits and vegetables, which are rich sources of $\mathrm{K}$, have a beneficial effect on BMD. A recent review highlights that any beneficial effect on $\mathrm{K}$ on bone may relate to the accompanying anion: fruits and vegetables are rich in bicarbonate precursors (for example, citrate), whereas milk, meat and cereal products contain fewer bicarbonate precursors $^{(9)}$. In contrast, a higher intake of $\mathrm{Na}$, another feature of modern diets, has been shown to increase $\mathrm{Ca}$ excretion and has been associated with lower BMD ${ }^{(10-11)}$. In one study, over 2 years urinary $\mathrm{Na}$ excretion was a significant determinant of bone loss at the hip and ankle sites in postmenopausal women $^{(12)}$. In another study a low-Na Dietary Approaches to Stop Hypertension (DASH)-type diet (high in $\mathrm{Ca}$ and fruits and vegetables) was found to affect bone turnover by decreasing bone formation by $8-11 \%$, and while resorption was further reduced by $16-18 \%$, the authors interpret this

Abbreviations: BMD, bone mineral density; BP, blood pressure; CTX, C-terminal telopeptide of type I collagen; DASH, Dietary Approaches to Stop Hypertension; HCLF, high-carbohydrate low-fat; LNAB, low-Na base-producing; NEAP, net endogenous acid production; PINP, propeptide of type 1 procollagen; PRAL, potential renal acid load.

* Corresponding author: Professor Caryl Nowson, fax +6139244 6017, email caryl.nowson@ deakin.edu.au 
as a net beneficial effect on $\mathrm{BMD}^{(13)}$. In older adults, adequate dietary protein also contributes to the maintenance of bone health $^{(14)}$, although it is unclear whether the source of the protein (animal or vegetable) is a major factor in determining the effect. Paradoxically, a higher animal to vegetable protein dietary composition has been reported to both increase the risk of hip fracture in postmenopausal women ${ }^{(15)}$, and decrease the risk of fracture in a similarly matched group of subjects ${ }^{(16)}$.

The present study aimed to compare the effects on blood pressure (BP) and bone turnover of a low-Na base-producing (LNAB) diet (based on the low-Na DASH diet), which included a serving of red meat on most days, compared with a high-carbohydrate low-fat (HCLF) diet, with a higher acid load. Both diets were designed to provide adequate dietary $\mathrm{Ca}$ and to be significantly different in dietary acid load, which was primarily achieved by a greater intake of breads and cereals in the HCLF diet. The LNAB diet was more representative of our ancestral diet and the HCLF diet was representative of a low-fat dietary pattern that restricts red meat, that many individuals attempt to follow to reduce the risk of CVD. The diets were designed to maintain body weight and energy intake. The results of these two diets on $\mathrm{BP}$ are reported elsewhere ${ }^{(17)}$.

\section{Subjects and methods}

\section{Study subjects and study design}

Subjects were recruited from the general community for this randomised, controlled parallel-design dietary intervention study. Women were eligible if they were experiencing menopausal symptoms or had passed through menopause and were not taking any hormone replacement therapy, had a BMI between 18 and $35 \mathrm{~kg} / \mathrm{m}^{2}$, and, before randomisation, had a seated office systolic BP $\geq 120$ and $<160 \mathrm{mmHg}$ or diastolic $\mathrm{BP} \geq 80$ and $<95 \mathrm{mmHg}$ at their screening visit, or had a home systolic $\mathrm{BP} \geq 116 \mathrm{mmHg}$ or diastolic $\mathrm{BP} \geq 78 \mathrm{mmHg}$ (average of $7 \mathrm{~d}$ ), or were classified as having prehypertension or stage 1 hypertension ${ }^{(18)}$. The BP criteria were designed to exclude those with low or normal BP. Subjects who were taking anti-hypertensive medication were included, provided they were willing to maintain their current therapy and dose. Subjects were excluded if they had experienced the menopause before they turned 43 years old, were taking Warfarin, Dilantin or medications for osteoporosis treatment such as bisphophonates, Fosamax, had been treated for cancer within the previous 3 years, had a cardiovascular event in the past 6 months, had insulin-dependent diabetes, consumed more than thirty standard alcoholic drinks/week or ate main meals outside the home more than twice per week. All subjects provided written informed consent before starting the study, which was approved by the Deakin University Human Research Ethics Committee.

Randomisation was stratified by BMI and anti-hypertensive use. Eligible subjects were randomly assigned to follow either the LNAB or HCLF diet for 14 weeks, during which they were seen five times, at weeks 2, 4, 8, 12 and 14. Phone follow-up was made at weeks 6 and 10. The LNAB diet was designed to have a low dietary acid load and the HCLF to have a high dietary acid load (Table 1), with a difference between diets of $19 \mathrm{mEq} / \mathrm{d}$ potential renal acid load $(\mathrm{PRAL})^{(19)}$ or $12 \mathrm{mEq} / \mathrm{d} \mathrm{NEAP}^{(20)}$. The LNAB diet was based on the low$\mathrm{Na}$ DASH diet and was rich in fruit and vegetables, lower in $\mathrm{Na}$ and higher in $\mathrm{K}, \mathrm{Mg}$ and lean red meat compared with the HCLF diet. Both the LNAB and HCLF diets were designed to include at least $1000 \mathrm{mg}$ dietary $\mathrm{Ca}$, but differed in the amount of lean red meat, fruit and vegetables, breads and cereals, and dietary $\mathrm{Na}$ (Table 1). Subjects in both diet groups were advised to use either poly- or monounsaturated margarines and cooking oil and the amount recommended was adjusted to meet energy requirements.

Each week, LNAB subjects received $810 \mathrm{~g}$ raw lean red meat (either beef, lamb, veal or combination) in $135 \mathrm{~g}$ serving sizes (reduced to about $100 \mathrm{~g}$ when cooked), low-Na multigrain bread $(75 \mathrm{mg} \mathrm{Na} / 100 \mathrm{~g}$ ), no-added-salt baked beans $(20 \mathrm{mg} \mathrm{Na} / 100 \mathrm{~g}$ ), salt-free margarine and low-Na stock powder (approximately $50 \mathrm{mg} \mathrm{Na} / 100 \mathrm{~g}$ ). HCLF subjects received regular-salt margarine and regular-salt baked beans as required. They were also provided with canned tuna as an incentive. Dietary counselling was provided by trained

Table 1. Dietary recommendations for 14-week intervention study

\begin{tabular}{|c|c|c|c|}
\hline & LNAB diet & HCLF diet & Comment \\
\hline Lean red meat & Six serves/week & $\leq$ Two serves/week & One serve $=100 \mathrm{~g}$ cooked \\
\hline Low-fat dairy products & $\geq$ Three serves/d & $\geq$ Three serves/d & Cheese was restricted in LNAB diet \\
\hline Fruit & $\geq$ Four serves/d & Two serves/d & One serve $=$ one medium fruit or $200 \mathrm{ml}$ juice \\
\hline Vegetables & $\geq$ Four serves/d & Two-three serves/d & $\begin{array}{l}\text { One serve = half cup of vegetables or one } \\
\text { cup of salad }\end{array}$ \\
\hline Fats/oils & $\geq$ Four teaspoons/d & $\geq$ Four teaspoons/d & Mono- or polyunsaturated \\
\hline Breads and cereals & $\leq$ Four serves/d* & $\geq$ Four serves/d† & One serve $=$ two slices bread \\
\hline Caffeine drinks & $\leq$ Four serves/d & $\leq$ Four serves/d & One serve $=$ one cup $(250 \mathrm{ml})$ \\
\hline Alcoholic drinks & $\leq$ Two serves/d & $\leq$ Two serves/d & $\begin{array}{l}\text { One serve = one standard drink containing } \\
10 \mathrm{~g} \text { alcohol }\end{array}$ \\
\hline Na intake & $60-70 \mathrm{mmol} / \mathrm{d}$ & & \\
\hline Vegetarian days & $\mathrm{N} / \mathrm{A}$ & $\geq 2 \mathrm{~d} /$ week & \\
\hline Potential renal acid load (mEq) & $-4 \mathrm{mEq} / \mathrm{d}$ & $+15 \mathrm{mEq} / \mathrm{d}$ & \\
\hline Net acid endogenous production (mEq) & $+42 \mathrm{mEq} / \mathrm{d}$ & $+54 \mathrm{mEq} / \mathrm{d}$ & \\
\hline
\end{tabular}

LNAB, low-Na base-producing; HCLF, high-carbohydrate low-fat; N/A, not applicable.

${ }^{*}$ Wholegrain.

†Choice of wholegrain or white. 
dietitians. To ensure that both groups had adequate $\mathrm{Ca}$ intake, subjects were encouraged to consume at least three serves of low-fat milk and dairy products daily, but the LNAB subjects were asked to restrict their cheese consumption due to its high $\mathrm{Na}$ content. LNAB subjects were also asked to consume wholegrain breads and unprocessed cereals but limit the consumption of breads and cereals to a maximum of four serves/d, while HCLF subjects were asked to consume at least four serves bread and cereals daily and they were encouraged to use wholegrain breads and unprocessed cereals.

\section{Dietary assessment}

Dietary adherence or compliance of subjects was assessed using measurements of $24 \mathrm{~h}$ urinary electrolyte excretion and the numbers of servings of six key food group components, namely red meat, milk and other dairy products, bread and cereals (wholegrain), fruit, vegetables, and fats and oils (Table 1). Subjects were asked to record their consumption of these key food group components in their food group diaries over a period of three consecutive days each week. Average daily numbers of servings of each key food group were then calculated for each 2 -week period.

Each fortnight subjects also completed a $24 \mathrm{~h}$ food record on the day before their visit. The average of two food records before randomisation was used as the baseline values, and the average of seven records kept during the intervention period was used for the intervention values. Data from the food records were analysed using Foodworks Professional Edition (version 4; Xyris Software, Brisbane, Qld, Australia). The actual red meat intake was estimated from these food records. PRAL and NEAP were calculated from the following equations $^{(19-21)}$ :

$\operatorname{PRAL}(\mathrm{mEq} / \mathrm{d})=(0.49 \times \operatorname{protein}(\mathrm{g} / \mathrm{d}))$

$$
\begin{aligned}
& +(0.037 \times \mathrm{P}(\mathrm{mg} / \mathrm{d}))-(0.021 \times \mathrm{K}(\mathrm{mg} / \mathrm{d})) \\
& -(0.026 \times \mathrm{Mg}(\mathrm{mg} / \mathrm{d})) \\
& -(0.013 \times \mathrm{Ca}(\mathrm{mg} / \mathrm{d}))
\end{aligned}
$$

$\operatorname{NEAP}(\mathrm{mEq} / \mathrm{d})=(54.5 \times \operatorname{protein}(\mathrm{g} / \mathrm{d}) / \mathrm{K}(\mathrm{mEq} / \mathrm{d}))-10 \cdot 2$.

\section{Assessments of body composition, physical activity and} biochemical parameters

Height was measured to the nearest centimetre using a free-standing stadiometer and body weight measured at each visit on a digital scale with subjects wearing light clothing and no shoes. Waist and hip circumferences were measured to the nearest centimetre. Total body fat mass was measured by dualenergy X-ray absorptiometry (DPX-L; Lunar, Madison, WI, USA) at baseline and at the end of the study at week 14 .

At least two $24 \mathrm{~h}$ urine collections were obtained at baseline and four during the intervention period at weeks $4,8,12$ and 14. Spot urine $\mathrm{pH}$ was measured at each visit on a freshly voided sample, and urinary electrolytes and creatinine were measured on $24 \mathrm{~h}$ urine collection using a Randox Daytona automated clinical chemistry Analyser (Antrim, UK, 2002). Blood samples were collected after subjects had fasted for at least $10 \mathrm{~h}$, once at baseline and three times during the intervention period at weeks 8, 12 and 14. Serum samples were stored at $-80^{\circ} \mathrm{C}$ until analysis of 25 -hydroxyvitamin D, parathyroid hormone and bone turnover markers.

Measurements were performed in duplicate on serum samples collected at baseline and week 14 for serum 25-hydroxyvitamin D and intact parathyroid hormone by RIA (DiaSorin Inc., Stillwater, MN, USA), and bone turnovermarkers. Serum osteocalcin and C-terminal telopeptide of type I collagen (CTX) were measured by ELISA (Nordic Bioscience Diagnostics, Herlev, Denmark), and intact $\mathrm{N}$-terminal propeptide of type 1 procollagen (PINP) was measured by RIA (Orion Diagnostica, Espoo, Finland). One additional assay was performed on samples collected at week 8 for PINP and CTX. Replicates had a CV of less than $15 \%$. Intra-assay $\mathrm{CV}$ for bone turnover markers were less than $10 \%$ (osteocalcin 3.9\%, PINP 9.4\%, CTX 7.0\%) and inter-assay CV were less than $8 \%$ (osteocalcin $4.6 \%$, PINP 7.1\%, CTX 7.0\%).

\section{Statistical analysis}

Data analyses were performed using SPSS for Windows (version 14.0, 2006; SPSS Inc., Chicago, IL, USA). Values presented are mean values with their standard errors. A simple $t$ test was used to assess differences between diet groups, and changes in parameters over the study period were evaluated by paired $t$ test. A repeated-measures oneway ANOVA test was performed on serum PINP and CTX at baseline, week 8 and week 14 to assess their changes over time. A Shapiro-Wilk test was performed on the main outcome variables to determine whether or not the data were normally distributed. Log transformation was performed on serum osteocalcin, PINP, CTX, and the urinary excretion of $\mathrm{Na}, \mathrm{K}$ and $\mathrm{Ca}$ as they were not normally distributed before the comparisons were made between diet groups; however, the geometric means were presented. A $\chi^{2}$ test was performed to evaluate the differences in proportions of subjects between the two diet groups. The Pearson correlation coefficient $(r)$ was used to determine the relationship between two variables. The level of significance was set at 0.05.

Based on results from Lin et al. ${ }^{(13)}$, forty-eight subjects in each group would have been sufficient to demonstrate an $18 \%$ difference in serum osteocalcin between the two diet groups after 3 months with a significance level of $5 \%$.

\section{Results}

Of the 246 women who attended a screening visit, 111 were eligible and were randomised into the dietary intervention (fifty-three LNAB, fifty-eight HCLF). Sixteen women dropped out of the study: four due to illness (one LNAB, three HCLF) and twelve (six LNAB, six HCLF) were unable to commit to the diet for the study length, leaving ninety-five subjects completing the dietary intervention (forty-six LNAB, fortynine HCLF). About $37 \%$ of these subjects (seventeen LNAB, eighteen HCLF) were receiving either single or combination anti-hypertensive therapy. 


\section{Baseline characteristics}

At baseline, subjects in the two diet groups were similar in regard to their age and body composition measurements. Of the ninety-five subjects, ninety $(95 \%)$ were postmenopausal for at least 1 year. The two diet groups were matched for menopausal stage (Table 2). The mean number of years past menopause was 9.4 (SEM 0.9) for the LNAB group and 9.3 (SEM 0.9) for the HCLF group. The HCLF group had higher intakes of total energy, protein, fat and carbohydrate; however, no significant differences between groups were observed in percentage energy derived from these macronutrients

Table 2. Descriptive characteristics of the study population at baseline

(Mean values with their standard errors)

\begin{tabular}{|c|c|c|c|c|c|c|c|}
\hline & \multicolumn{3}{|c|}{ LNAB diet } & \multicolumn{3}{|c|}{ HCLF diet } & \multirow[b]{2}{*}{ Group difference: $P$} \\
\hline & $n$ & Mean & SEM & $n$ & Mean & SEM & \\
\hline Age (years) & 46 & $60 \cdot 0$ & 0.7 & 49 & 58.4 & 0.7 & $0 \cdot 12$ \\
\hline Age range (years) & 46 & \multicolumn{2}{|c|}{$50.7-71.9$} & 49 & \multicolumn{2}{|c|}{$48.9-68.5$} & \\
\hline Anti-hypertensive use & 46 & & & 49 & & & 0.86 \\
\hline Number of subjects & & \multicolumn{2}{|c|}{17} & & \multicolumn{2}{|c|}{18} & \\
\hline$\%$ & & \multicolumn{2}{|c|}{$37 \cdot 0$} & & \multicolumn{2}{|c|}{$36 \cdot 7$} & \\
\hline $\begin{array}{l}\text { Amenorrhoea } \\
\text { Less than } 1 \text { year }\end{array}$ & 46 & & & 49 & & & $0.39^{*}$ \\
\hline$n$ & & \multicolumn{2}{|c|}{1} & & \multicolumn{2}{|c|}{4} & \\
\hline $\begin{array}{c}\% \\
1-10 \text { years }\end{array}$ & & \multicolumn{2}{|c|}{$2 \cdot 2$} & & \multicolumn{2}{|c|}{$8 \cdot 2$} & \\
\hline$n$ & & \multicolumn{2}{|c|}{22} & & \multicolumn{2}{|c|}{24} & \\
\hline$\%$ & & \multicolumn{2}{|c|}{$47 \cdot 8$} & & \multicolumn{2}{|c|}{$49 \cdot 0$} & \\
\hline$\geq 10$ years & & & & & \multirow{2}{*}{\multicolumn{2}{|c|}{21}} & \\
\hline$n$ & & \multicolumn{2}{|c|}{23} & & & & \\
\hline$\%$ & & & & & & & \\
\hline Time past menopause (years) & 46 & 9.4 & 0.9 & 49 & $9 \cdot 3$ & 0.9 & 0.88 \\
\hline Range of time past menopause (years) & & & & & & & \\
\hline Body composition measurements & & & & & & & \\
\hline Weight (kg) & 46 & $78 \cdot 0$ & $2 \cdot 0$ & 49 & $79 \cdot 0$ & 1.7 & 0.71 \\
\hline BMI $\left(\mathrm{kg} / \mathrm{m}^{2}\right)$ & 46 & 29.5 & 0.7 & 49 & $29 \cdot 7$ & 0.6 & 0.79 \\
\hline Waist circumference $(\mathrm{cm})$ & 45 & 97.5 & 1.9 & 49 & $98 \cdot 2$ & 1.6 & 0.79 \\
\hline Hip circumference $(\mathrm{cm})$ & 45 & 111.4 & 1.4 & 49 & $111 \cdot 1$ & 1.3 & 0.86 \\
\hline Total body \% fat mass & 43 & $45 \cdot 1$ & 1.0 & 43 & $45 \cdot 0$ & $1 \cdot 1$ & 0.97 \\
\hline Total body $\%$ lean mass & 43 & 54.9 & 1.0 & 43 & $55 \cdot 0$ & $1 \cdot 1$ & 0.97 \\
\hline Dietary nutrient intake & & & & & & & \\
\hline Energy $(\mathrm{kJ} / \mathrm{d})$ & 44 & 6607 & 298 & 49 & 7926 & 281 & 0.002 \\
\hline Protein $(\mathrm{g} / \mathrm{d})$ & 44 & $77 \cdot 0$ & 3.4 & 49 & $89 \cdot 2$ & 3.4 & 0.014 \\
\hline Fat $(g / d)$ & 44 & $56 \cdot 8$ & 3.8 & 49 & $72 \cdot 1$ & $3 \cdot 7$ & 0.004 \\
\hline Carbohydrate $(\mathrm{g} / \mathrm{d})$ & 44 & $182 \cdot 7$ & $9 \cdot 6$ & 49 & $215 \cdot 0$ & $8 \cdot 8$ & 0.015 \\
\hline Fibre $(g / d)$ & 44 & $23 \cdot 2$ & $1 \cdot 2$ & 49 & $26 \cdot 5$ & $1 \cdot 1$ & 0.046 \\
\hline Energy from protein (\%) & 44 & 20.4 & 0.7 & 49 & $19 \cdot 4$ & 0.6 & 0.30 \\
\hline Energy from fat $(\%)$ & 44 & $30 \cdot 9$ & $1 \cdot 2$ & 49 & $32 \cdot 8$ & 0.9 & 0.20 \\
\hline Energy from carbohydrate (\%) & 44 & $46 \cdot 6$ & $1 \cdot 3$ & 49 & 45.9 & 1.0 & 0.66 \\
\hline $\mathrm{Na}(\mathrm{mg} / \mathrm{d})$ & 44 & 2180 & 120 & 49 & 2272 & 137 & 0.62 \\
\hline $\mathrm{K}(\mathrm{mg} / \mathrm{d})$ & 44 & 3018 & 136 & 49 & 3238 & 116 & 0.22 \\
\hline $\mathrm{Ca}(\mathrm{mg} / \mathrm{d})$ & 44 & 824 & 60 & 49 & 829 & 42 & 0.94 \\
\hline$M g(m g / d)$ & 44 & 294 & 15 & 49 & 332 & 10 & 0.04 \\
\hline$P(\mathrm{mg} / \mathrm{d})$ & 44 & 1331 & 64 & 49 & 1501 & 54 & 0.04 \\
\hline Potential renal acid load $(\mathrm{mEq} / \mathrm{d})$ & 44 & $5 \cdot 2$ & $2 \cdot 0$ & 49 & $11 \cdot 8$ & 2.9 & 0.07 \\
\hline Net endogenous acid production ( $\mathrm{mEq} / \mathrm{d}$ ) & 44 & $45 \cdot 1$ & 1.8 & 49 & $50 \cdot 6$ & $2 \cdot 1$ & 0.06 \\
\hline Urinary $\mathrm{pH}$ (spot urine) & 45 & $6 \cdot 3$ & $0 \cdot 1$ & 49 & 6.4 & $0 \cdot 1$ & 0.40 \\
\hline Urinary $\mathrm{Na}(\mathrm{mmol} / \mathrm{d}) \dagger$ & 46 & 107.5 & $6 \cdot 1$ & 49 & $109 \cdot 0$ & $5 \cdot 8$ & 0.78 \\
\hline Urinary $\mathrm{K}(\mathrm{mmol} / \mathrm{d}) \dagger$ & 46 & 64.0 & $4 \cdot 2$ & 49 & 64.1 & 2.5 & 0.99 \\
\hline Urinary $\mathrm{Ca}(\mathrm{mmol} / \mathrm{d}) \dagger$ & 46 & 3.0 & 0.3 & 49 & $3 \cdot 1$ & 0.2 & 0.63 \\
\hline Urinary $\mathrm{Mg}(\mathrm{mmol} / \mathrm{d})$ & 46 & $2 \cdot 9$ & 0.2 & 49 & $3 \cdot 1$ & 0.1 & 0.52 \\
\hline Urinary $\mathrm{Cl}(\mathrm{mmol} / \mathrm{d})$ & 46 & 113.4 & $12 \cdot 6$ & 49 & 109.5 & $6 \cdot 2$ & 0.78 \\
\hline Urinary phosphate $(\mathrm{mmol} / \mathrm{d})$ & 46 & $22 \cdot 3$ & 1.4 & 49 & $23 \cdot 2$ & $1 \cdot 0$ & 0.59 \\
\hline Urinary urea $(\mathrm{mmol} / \mathrm{d})$ & 46 & 294.0 & $19 \cdot 4$ & 49 & 319.1 & $11 \cdot 8$ & 0.27 \\
\hline Serum osteocalcin $(\mathrm{ng} / \mathrm{ml}) \dagger$ & 45 & $12 \cdot 9$ & 0.8 & 47 & $14 \cdot 1$ & $1 \cdot 1$ & 0.38 \\
\hline Serum PINP(ng/ml) $\dagger$ & 46 & $56 \cdot 7$ & 4.4 & 47 & $49 \cdot 8$ & $2 \cdot 8$ & $0 \cdot 18$ \\
\hline Serum CTX (ng/ml)† & 46 & 0.3 & 0.03 & 47 & 0.3 & 0.03 & 0.78 \\
\hline Serum 25(OH)D (nmol/l) & 45 & $50 \cdot 6$ & $2 \cdot 1$ & 47 & $51 \cdot 2$ & $2 \cdot 4$ & 0.85 \\
\hline Serum PTH (ng/l) & 46 & 21.9 & $1 \cdot 3$ & 47 & $25 \cdot 3$ & $2 \cdot 1$ & 0.18 \\
\hline
\end{tabular}

LNAB, low-Na base-producing; HCLF, high-carbohydrate low-fat; PINP, procollagen type I N-terminal propeptide; CTX, C-terminal telopeptide of type I collagen; 25(OH)D, 25-hydroxyvitamin D; PTH, intact parathyroid hormone.

${ }^{*} \chi^{2}$ test.

†Log transformation was performed on non-normally distributed data before the comparison between groups was made. 
(Table 2). They were also significantly different in terms of the daily intakes of fibre, $\mathrm{Mg}$ and $\mathrm{P}$. No significant differences were observed between diet groups for any other parameters.

\section{Dietary intervention}

Both the LNAB and HCLF diets resulted in significant changes in nutrient intakes (Table 3), consistent with the aims of the study. Notably, PRAL, as a measure of the dietary acid load, was significantly decreased from baseline in the LNAB group from week 2 (Fig. 1 and Table 3) and was significantly lower than that of the HCLF group throughout the intervention period (Fig. 1). On the base-producing diet, the LNAB group had an average PRAL of $-9.0 \mathrm{mEq} / \mathrm{d}$ and NEAP of $38.0 \mathrm{mEq} / \mathrm{d}$, while those on the HCLF diet had PRAL of $14.1 \mathrm{mEq} / \mathrm{d}$ and NEAP of $52.8 \mathrm{mEq} / \mathrm{d}$. The inclusion of lean red meat in the LNAB group resulted in an increase of protein by 12.2 (SEM 3.1) g/d and total fat by 12.1 (SEM 3.4) $\mathrm{g} / \mathrm{d}$; however, there was no significant change in percentage energy derived from protein and percentage energy from protein did not differ between the two diet groups. After adjustment for energy, compared with the HCLF diet, the LNAB group reported a greater intake of $\mathrm{K}(35 \%)$ and lower intake of $\mathrm{Na}(53 \%)$ and $\mathrm{Ca}(13 \%)$.

Food records showed that, during the intervention period, the LNAB subjects consumed on average 85 (SEM 5) g cooked red meat per d, which was an increase of $56 \mathrm{~g} / \mathrm{d}$ from baseline, and $62 \mathrm{~g}$ more red meat per $\mathrm{d}$ than the HCLF group. Analysis of weekly food group diaries confirmed red meat intakes, indicating average daily red meat intake increased from 0.5 servings at baseline to 0.9 servings during the intervention period $(P<0.0001)$ in the LNAB group (Table 4$)$. The LNAB group also increased consumption of milk by $0 \cdot 3$ servings/d $(P<0 \cdot 0001)$, other dairy products by 0.2 servings $/ \mathrm{d}(P=0.033)$, fruit by 1.5 servings $/ \mathrm{d}(P<0.0001)$ and vegetables by one serving/d $(P=0.006)$, as shown in Table 4. In contrast, HCLF subjects reduced their red meat consumption by 0.2 servings/d $(P<0.0001)$, increased intakes of milk by 0.3 servings/d and other dairy products by 0.6 servings/d (both $P<0.0001$ ) from baseline. Overall the LNAB group had a greater increase in fruit, vegetables and red meat, but less of an increase in dairy products other than milk, compared with the HCLF group. During the intervention period, both groups reported using more fats and oils in their diet compared with baseline.

\section{Change in body weight and total body fat mass}

Although both diets were designed to maintain body weight, at the end of the study, there was a small, but significant, reduction in body weight in both groups, by 1.2 (SEM $0 \cdot 3$ ) $\mathrm{kg}$ for the LNAB group and 1.0 (SEM 0.3 ) $\mathrm{kg}$ for the HCLF group. However, there was no significant difference in weight reduction between the groups. Likewise, measurements of total body fat by dual-energy X-ray absorptiometry showed that both the LNAB and HCLF groups had a similar small reduction in total body percentage fat mass: 0.8 (SEM 0.2) $\mathrm{kg}$ in the LNAB subjects and 0.7 (SEM 0.2) $\mathrm{kg}$ in the HCLF subjects (both $P<0 \cdot 01$ ).

\section{Associations of urinary electrolyte excretion and dietary acid load with bone turnover markers}

The $24 \mathrm{~h}$ urinary analysis confirmed that a high level of compliance was achieved in both diet groups. During the dietary intervention period, the LNAB group had a 26 (SEM 6) \% fall in urinary $\mathrm{Na}$, and a trend for a fall in Ca excretion of 0.4 (SEM 0.2$) \mathrm{mmol} / \mathrm{d}(P=0.07)$, and an increase in $\mathrm{K}$ excretion of $6 \cdot 8$ (SEM 3.6) $\mathrm{mmol} / \mathrm{d}(P=0 \cdot 07)$. The HCLF group had no significant change in urinary electrolyte excretion, but their urinary $\mathrm{pH}$ was reduced by $0 \cdot 2(P=0 \cdot 03$; Table 5$)$. When subjects were pooled, PRAL during the intervention period was correlated with urinary $\mathrm{Na}(r 0.59 ; P<0 \cdot 0001), \mathrm{K}(r-0 \cdot 31$; $P=0.002)$ and $\mathrm{Ca}(r 0.33 ; P=0.0008)$ excretion. The reduction in urinary $\mathrm{Na}$ was associated with a reduction in urinary $\mathrm{Ca}$, within groups, LNAB $(r 0 \cdot 32 ; P=0 \cdot 03)$ and $\operatorname{HCLF}(r \quad 0 \cdot 34$;

Table 3. Change in daily nutrient intake and dietary acid load from baseline to the intervention period (average of seven fortnightly $24 \mathrm{~h}$ food records) (Mean values with their standard errors)

\begin{tabular}{|c|c|c|c|c|c|c|c|}
\hline & \multicolumn{3}{|c|}{ LNAB diet } & \multicolumn{3}{|c|}{ HCLF diet } & \multirow[b]{2}{*}{ Group difference: $P$} \\
\hline & $n$ & Mean & SEM & $n$ & Mean & SEM & \\
\hline Energy (kJ) & 44 & 491.4 & $246 \cdot 2$ & 49 & -444.9 & 302.5 & 0.02 \\
\hline Protein $(\mathrm{g})$ & 44 & $12 \cdot 2^{\star \star *}$ & $3 \cdot 1$ & 49 & -1.4 & 3.6 & 0.006 \\
\hline Fat $(g)$ & 44 & $12 \cdot 1^{\star \star \star}$ & 3.4 & 49 & $-5 \cdot 8$ & 3.9 & 0.001 \\
\hline Carbohydrate (g) & 44 & $21 \cdot 4^{\star}$ & $8 \cdot 3$ & 49 & $-10 \cdot 3$ & 9.5 & 0.02 \\
\hline Fibre $(g)$ & 44 & $4 \cdot 2^{\star *}$ & $1 \cdot 2$ & 49 & $-3 \cdot 0^{\star *}$ & $1 \cdot 1$ & $<0.0001$ \\
\hline Energy from protein (\%) & 44 & 0.0 & 0.7 & 49 & 0.8 & 0.7 & 0.46 \\
\hline Energy from fat $(\%)$ & 44 & $2 \cdot 0$ & $1 \cdot 2$ & 49 & $-1 \cdot 1$ & 1.0 & 0.04 \\
\hline Energy from carbohydrate (\%) & 44 & $-1 \cdot 2$ & $1 \cdot 2$ & 49 & 0.8 & 1.0 & 0.20 \\
\hline $\mathrm{Na}(\mathrm{mg})$ & 44 & $-1140^{\star \star \star \star}$ & 130 & 49 & -62 & 139 & $<0.0001$ \\
\hline $\mathrm{K}(\mathrm{mg})$ & 44 & $1106^{\star \star \star \star}$ & 157 & 49 & -175 & 115 & $<0.0001$ \\
\hline $\mathrm{Ca}(\mathrm{mg})$ & 44 & 119 & 61 & 49 & $287^{\star \star \star \star}$ & 56 & 0.04 \\
\hline $\mathrm{Mg}(\mathrm{mg})$ & 44 & $33^{*}$ & 13 & 49 & -9 & 11 & 0.02 \\
\hline$P(m g)$ & 44 & $140^{*}$ & 55 & 49 & 76 & 59 & 0.43 \\
\hline Potential renal acid load (mEq) & 44 & $-14 \cdot 5^{\star \star \star \star}$ & $2 \cdot 7$ & 49 & $2 \cdot 3$ & $3 \cdot 2$ & 0.0002 \\
\hline Net acid endogenous production (mEq) & 44 & $-7 \cdot 1^{\star \star}$ & $2 \cdot 3$ & 49 & $2 \cdot 2$ & $2 \cdot 5$ & 0.007 \\
\hline
\end{tabular}

LNAB, low-Na base-producing; HCLF, high-carbohydrate low-fat

Difference from baseline was significant: ${ }^{\star} P<0.05,{ }^{\star \star} P<0.01,{ }^{\star \star \star} P<0.001,{ }^{\star \star \star \star} P<0.0001$ (paired $t$ tests). 


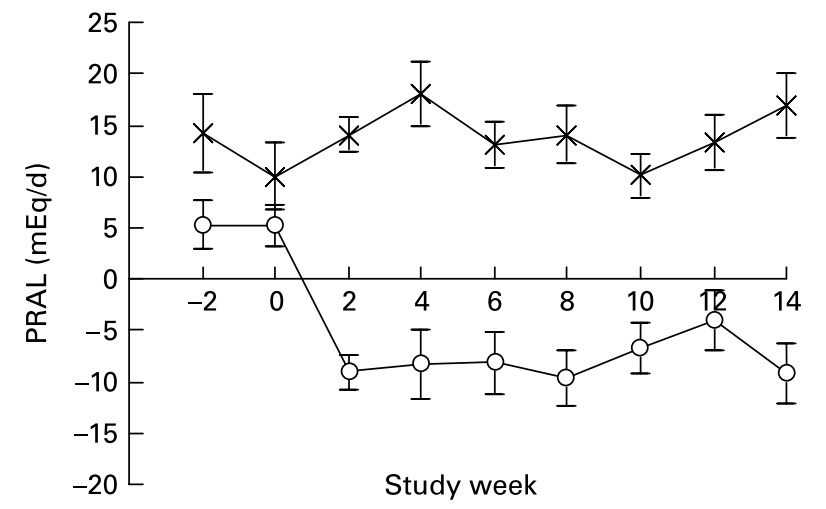

Fig. 1. The effect of the low-Na base-producing diet $(O ; n$ 46) and the high-carbohydrate low-fat diet $(x ; n 49)$ on potential renal acid load (PRAL) over the 14-week study. Values are means, with standard errors represented by vertical bars.

$P=0.02)$ and when both groups were pooled ( $r$ 0.39; $P<0.0001)$ where a $40 \mathrm{mmol}$ reduction in urinary $\mathrm{Na}$ was associated with a reduction of $16 \mathrm{mg}$ urinary $\mathrm{Ca}$ excretion.

\section{Change in bone turnover markers}

After a 14-week period of the intervention, there was a 23 (SEM 5) \% increase in bone resorption as assessed by serum
CTX levels, but no change was observed in serum osteocalcin both in the LNAB and HCLF groups (Table 6 and Fig. 2). Whilst there was no change in osteocalcin, the HCLF group had an increase in PINP, by 11 (SEM 4) \% $(P=0.003)$, which was different from the change seen in the LNAB group (difference between groups of 13 (SEM 5) \%). Results of the repeated-measures ANOVA tests showed that the LNAB and HCLF groups had a similar trend of changes in serum CTX, while no trend of changes in serum PINP was observed in either group (Fig. 2).

There were positive relationships only in the HCLF group between the change in CTX and the change in PRAL $(r 0.33 ; P=0.02 ; n 47)$ and in NEAP $(r 0.38 ; P=0.01 ; n 47)$, and also between the change in osteocalcin and the change in PRAL $(r 0.31 ; P=0.03 ; n$ 47); where dietary acid load increased, so did CTX and osteocalcin. These associations were not observed in the LNAB diet group. Neither the change in PRAL nor NEAP was associated with the change in serum PNIP in either group.

\section{Discussion}

We did not find any difference between the two diets for change in bone resorption, as both groups has a similar $23 \%$ increase in CTX, although there was a small difference in PINP, a marker of bone formation. One diet was based on the low-Na DASH diet ${ }^{(22)}$, which included the consumption

Table 4. Intakes of key food group components at baseline and during the intervention period (average of seven fortnightly food group diary assessments)

(Mean values with their standard errors)

\begin{tabular}{|c|c|c|c|c|c|c|c|}
\hline & \multicolumn{3}{|c|}{ LNAB diet } & \multicolumn{3}{|c|}{ HCLF diet } & \multirow[b]{2}{*}{ Group difference: $P$} \\
\hline & $n$ & Mean & SEM & $n$ & Mean & SEM & \\
\hline \multicolumn{8}{|c|}{ Red meat (servings/d) } \\
\hline Baseline & 46 & 0.5 & 0.0 & 49 & 0.5 & 0.0 & 0.35 \\
\hline Intervention & 46 & 0.9 & 0.0 & 49 & 0.3 & 0.0 & $<0.0001$ \\
\hline Change & 46 & $0.5^{\star \star \star}$ & $0 \cdot 0$ & 49 & $-0 \cdot 2^{\star \star \star}$ & 0.0 & $<0.0001$ \\
\hline \multicolumn{8}{|c|}{ Milk (servings/d) } \\
\hline Baseline & 46 & $0 \cdot 8$ & $0 \cdot 1$ & 49 & 0.9 & 0.1 & 0.40 \\
\hline Intervention & 46 & $1 \cdot 2$ & 0.1 & 49 & 1.3 & 0.1 & 0.34 \\
\hline Change & 46 & $0.3^{\star \star \star}$ & $0 \cdot 1$ & 49 & $0.3^{\star \star \star}$ & 0.1 & 0.90 \\
\hline \multicolumn{8}{|c|}{ Dairy products (servings/d) } \\
\hline Baseline & 46 & 0.8 & 0.1 & 49 & 0.7 & 0.1 & 0.52 \\
\hline Intervention & 46 & 1.0 & $0 \cdot 1$ & 49 & $1 \cdot 3$ & $0 \cdot 1$ & 0.0005 \\
\hline Change & 46 & $0.2^{*}$ & 0.1 & 49 & $0.6^{\star \star *}$ & 0.1 & 0.0008 \\
\hline \multicolumn{8}{|c|}{ Bread (servings/d) } \\
\hline Baseline & 46 & $3 \cdot 1$ & 0.2 & 49 & 4.3 & 0.2 & 0.0003 \\
\hline Intervention & 46 & $3 \cdot 1$ & $0 \cdot 1$ & 49 & 4.7 & 0.2 & $<0.0001$ \\
\hline Change & 46 & 0.0 & 0.2 & 49 & 0.5 & 0.3 & 0.16 \\
\hline \multicolumn{8}{|c|}{ Fruit (servings/d) } \\
\hline Baseline & 46 & $2 \cdot 4$ & 0.2 & 49 & $2 \cdot 3$ & 0.2 & 0.62 \\
\hline Intervention & 46 & 3.9 & 0.2 & 49 & $2 \cdot 2$ & 0.1 & $<0.0001$ \\
\hline Change & 46 & $1.5^{\star \star \star}$ & 0.2 & 49 & -0.1 & 0.1 & $<0.0001$ \\
\hline \multicolumn{8}{|c|}{ Vegetables (servings/d) } \\
\hline Baseline & 46 & $2 \cdot 7$ & 0.2 & 49 & 2.5 & 0.1 & 0.57 \\
\hline Intervention & 46 & 3.6 & 0.2 & 49 & $2 \cdot 6$ & 0.1 & $<0.0001$ \\
\hline Change & 46 & $1 \cdot 0^{\star \star \star}$ & 0.2 & 49 & 0.1 & 0.1 & $<0.0001$ \\
\hline \multicolumn{8}{|c|}{ Fat and oils (servings/d) } \\
\hline Baseline & 46 & 0.7 & 0.1 & 49 & 1.1 & 0.1 & 0.004 \\
\hline Intervention & 46 & 1.3 & 0.1 & 49 & 1.9 & 0.1 & 0.01 \\
\hline Change & 46 & $0.6^{\star \star *}$ & 0.1 & 49 & $0.8^{\star \star *}$ & 0.2 & 0.26 \\
\hline
\end{tabular}

LNAB, low-Na base-producing; HCLF, high-carbohydrate low-fat.

Difference from baseline was significant: ${ }^{*} P<0.05,{ }^{* \star *} P<0.001$ (paired $t$ tests). 
Table 5. Change in spot urine $\mathrm{pH}$ and $24 \mathrm{~h}$ urinary electrolyte excretion from baseline to the intervention period (average of four urine collections) (Mean values with their standard errors)

\begin{tabular}{|c|c|c|c|c|c|c|c|}
\hline & \multicolumn{3}{|c|}{ LNAB diet } & \multicolumn{3}{|c|}{ HCLF diet } & \multirow[b]{2}{*}{ Group difference: $P$} \\
\hline & $n$ & Mean & SEM & $n$ & Mean & SEM & \\
\hline Spot urine $\mathrm{pH}$ & 45 & 0.0 & 0.1 & 49 & $-0.2^{*}$ & 0.1 & 0.14 \\
\hline $\mathrm{Na}(\mathrm{mmol})$ & 46 & $-38 \cdot 4^{\star \star \star \star}$ & 6.9 & 49 & 3.5 & $5 \cdot 1$ & $<0.0001$ \\
\hline $\mathrm{K}(\mathrm{mmol})$ & 46 & $6 \cdot 8$ & 3.6 & 49 & $-1 \cdot 2$ & $2 \cdot 6$ & 0.08 \\
\hline $\mathrm{Ca}(\mathrm{mmol})$ & 46 & -0.4 & 0.2 & 49 & 0.2 & 0.2 & 0.02 \\
\hline $\mathrm{Mg}(\mathrm{mmol})$ & 46 & 0.2 & 0.2 & 49 & 0.2 & 0.2 & 0.89 \\
\hline $\mathrm{Cl}(\mathrm{mmol})$ & 46 & $-42 \cdot 2^{\star \star}$ & $12 \cdot 7$ & 49 & 3.1 & $5 \cdot 2$ & 0.001 \\
\hline Phosphate (mmol) & 46 & -1.3 & $1 \cdot 2$ & 49 & 0.8 & 1.0 & 0.20 \\
\hline Urea $(\mathrm{mmol})$ & 46 & $1 \cdot 1$ & $16 \cdot 1$ & 49 & 3.0 & $12 \cdot 2$ & 0.92 \\
\hline $\mathrm{Na} \mathrm{K}$ ratio & 46 & $-0.8^{\star * \star *}$ & 0.1 & 49 & 0.1 & 0.1 & $<0.0001$ \\
\hline
\end{tabular}

LNAB, low-Na base-producing; HCLF, high-carbohydrate low-fat.

Difference from baseline was significant: ${ }^{\star} P<0.05$, ${ }^{\star \star} P<0.01$, ${ }^{\star \star \star \star} P<0.0001$ (paired $t$ tests).

of meat on most days and had a low dietary acid load (LNAB), and the other was a HCLF diet generally recommended to reduce cardiovascular risk, which had a relatively higher dietary acid load. The present results differ from those of Lin et al. ${ }^{(13)}$ who demonstrated that a low-Na DASH-type diet for $30 \mathrm{~d}$ reduced CTX (bone resorption) by 16-18\% and also resulted in a fall in serum osteocalcin by $8-11 \%$. It has been proposed that Westernised diets that favour a net acid-producing environment may affect bone metabolism adversely by increasing bone resorption. In vitro experiments have shown that administration of exogenous acids causes the release of bone mineral base into the systemic circulation $^{(23,24)}$, but this has not been confirmed in vivo, as the body has a number of efficient buffering mechanisms to prevent significant changes in serum $\mathrm{pH}$.

The physiological significance of the $23 \%$ increase in CTX observed in the present study is not clear as there are few studies assessing this in 'healthy' women in this age group. Our group primarily included postmenopausal women, and increases in bone resorption are frequently seen in women postmenopause. Postmenopausal women have elevated levels of bone resorption markers compared with premenopausal women, particularly CTX, which has been found to be $64 \%$ higher in postmenopausal women ${ }^{(25)}$. It has been proposed that consuming a diet with a high acid load results in an increased risk of chronic low-grade metabolic acidosis. A high acid environment is associated with a negative $\mathrm{Ca}$ balance and increased bone loss ${ }^{(26,27)}$, and a reduction in extracellular $\mathrm{pH}$, even within the physiological range, has been found to increase osteoclastic activity ${ }^{(28)}$. Accordingly, it would be expected that if there were an effect of dietary acid load on bone health, this would be reflected in the rate of bone resorption; however, we found no such effect with a high dietary acid load on bone resorption. Few studies have assessed changes in bone resorption with dietary interventions. One study conducted in young men found a $12.5 \%$ increase in serum CTX after consumption of 2.5 litres Coca Cola per d, compared with those who consumed 2.5 litres of low-fat milk $^{(29)}$

Both diets in the present study were designed to maintain body weight. Subjects were encouraged to consume more monounsaturated and/or polyunsaturated fats and oils in order to meet their energy requirements. However, it was found that, after 14 weeks of intervention, both groups experienced a small, but significant, fall in body weight. This is commonly seen when individuals participate in dietary

Table 6. Change in serum bone markers, 25-hydroxyvitamin $\mathrm{D}(25(\mathrm{OH}) \mathrm{D})$ and intact parathyroid hormone $(\mathrm{PTH})$ from baseline to week 14 (Mean values with their standard errors)

\begin{tabular}{|c|c|c|c|c|c|c|c|}
\hline & \multicolumn{3}{|c|}{ LNAB diet } & \multicolumn{3}{|c|}{ HCLF diet } & \multirow[b]{2}{*}{ Group difference: $P$} \\
\hline & $n$ & Mean & SEM & $n$ & Mean & SEM & \\
\hline \multicolumn{8}{|l|}{ Serum osteocalcin } \\
\hline Change (ng/ml) & 45 & 0.4 & 0.7 & 47 & -0.4 & 0.7 & 0.40 \\
\hline Percentage change & 45 & $7 \cdot 1$ & $4 \cdot 8$ & 47 & $5 \cdot 7$ & 4.9 & 0.84 \\
\hline \multicolumn{8}{|l|}{ Serum PINP(ng/ml) } \\
\hline Change $(\mathrm{ng} / \mathrm{ml})$ & 46 & $-2 \cdot 0$ & $2 \cdot 0$ & 47 & $3 \cdot 4^{\star}$ & 1.5 & 0.032 \\
\hline Percentage change & 46 & -1.6 & 3.2 & 47 & $11 \cdot 0^{\star *}$ & 3.6 & 0.010 \\
\hline \multicolumn{8}{|l|}{ Serum CTX $(\mathrm{ng} / \mathrm{ml})$} \\
\hline Change $(\mathrm{ng} / \mathrm{ml})$ & 46 & 0.03 & 0.02 & 47 & $0.04^{\star}$ & 0.01 & $0 \cdot 81$ \\
\hline Percentage change & 46 & $23 \cdot 1^{\star *}$ & $7 \cdot 7$ & 47 & $23 \cdot 3^{\star \star \star}$ & $6 \cdot 2$ & 0.99 \\
\hline Serum 25(OH)D (nmol/l) & 45 & -3.9 & $2 \cdot 1$ & 47 & -0.9 & $2 \cdot 2$ & 0.34 \\
\hline Serum PTH (ng/l) & 46 & -0.7 & $1 \cdot 7$ & 47 & $2 \cdot 2$ & 1.5 & 0.20 \\
\hline
\end{tabular}

LNAB, low-Na base-producing; HCLF, high-carbohydrate low-fat; PINP, procollagen type I N-terminal propeptide; CTX, C-terminal telopeptide of type I collagen Difference from baseline to week 14 was significant: * $P<0.05$, ${ }^{\star \star} P<0.01$, ${ }^{\star \star \star} P<0.001$ (paired $t$ tests). 

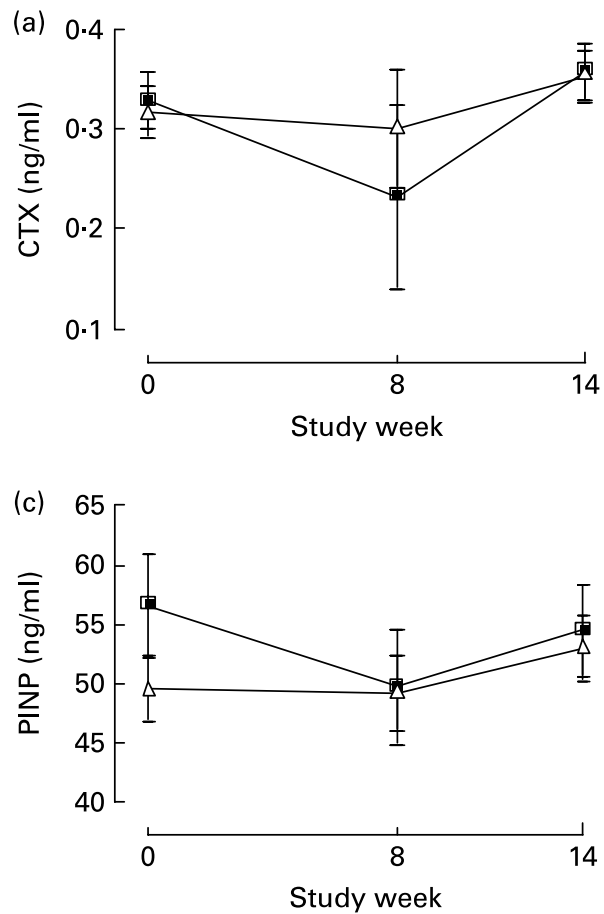
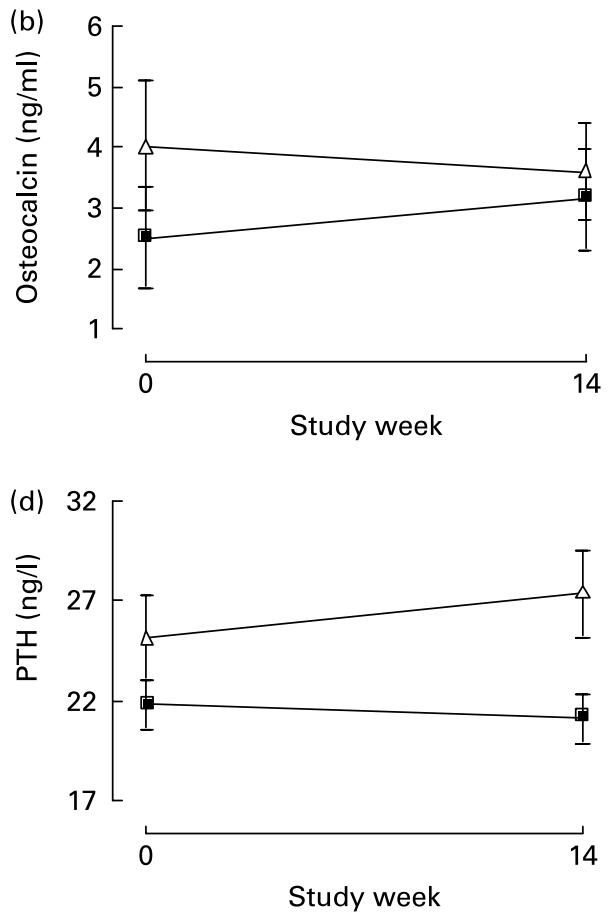

Fig. 2. The effect of the low-Na base-producing diet $(\mathbf{\square} ; n$ 46) and the high-carbohydrate low-fat diet $(\triangle ; n$ 49) on serum bone markers: (a) C-terminal telopeptide of type I collagen (CTX); (b) osteocalcin; (c) propeptide of type 1 procollagen (PINP); (d) parathyroid hormone (PTH). Values are means, with standard errors represented by vertical bars.

studies, particularly those that restrict high-fat foods. One study, in elderly women, found that over 12 months, the group that gained more weight (about $2.5 \mathrm{~kg}$ ) had a significant reduction of $32 \%$ in serum CTX at 3 months ${ }^{(30)}$. Accordingly the small fall in body weight could have contributed to the small increase in bone resorption seen in both groups. Consistent with this proposition, we found, when pooling the data from the two groups, that weight loss was associated with increased CTX $(r-0.23 ; P=0.002)$.

The $11.0 \%$ increase in PINP we observed in the HCLF group at the end of the study was relatively small compared with the change observed in hormone replacement therapy and other drug therapies ${ }^{(31,32)}$, but it was comparable with the $11.3 \%$ increase seen in a group of postmenopausal women after 16 weeks on Pravastatin therapy ${ }^{(33)}$. The increase in PINP experienced by the higher-acid load diet group could indicate an adverse effect, indicating increased bone turnover, or it may result, in the long term, in maintenance of bone mass.

\section{Dietary acid load and bone turnover}

We achieved a difference in dietary acid load between groups which was confirmed by an decrease in spot urine $\mathrm{pH}$ in the HCLF group, and a difference in reported nutrient intakes, as well as an increase in urinary $\mathrm{K}$ and lower $\mathrm{Na}$ in the LNAB group. We achieved these differences through manipulation of dietary intake utilising a different combination of food groups (more fruit and vegetables in the LNAB diet and more cereals in the HCLF diet group) rather than relying on supplements. This approach is more likely to result in differences between groups in associated nutrients and minerals (which may have additional benefits), evident in different dietary patterns.
This is in contrast to altering the acid-base balance with single supplements, which may have different effects from a food-based intervention. Results from a 2-year study indicated no reduction in bone turnover or increased BMD in healthy postmenopausal women supplemented with potassium citrate $^{(34)}$. As suggested by Macdonald et al. a change in acid load may not be significant for those with adequate dietary $\mathrm{Ca}$, but may only exert a significant adverse effect on bone health when coupled with a low-Ca diet ${ }^{(34)}$. Therefore, we may not have been able to detect any effect of acid load on bone resorption as both groups had a reasonable $\mathrm{Ca}$ intake, which was higher than their usual diets.

Dietary acid load did not appear to increase bone turnover, as we could not detect any association of PRAL or NEAP with any of the bone turnover markers. The present results confirm those of a longer-term, randomised controlled study over 2 years that compared potassium citrate supplementation with a diet high in fruits and vegetables, and found that dietary acid load had no effect on bone mineral homeostasis in postmenopausal women ${ }^{(34)}$. It is possible that factors other than acid load drive bone turnover on $\mathrm{Ca}$-adequate diets. It should be noted that in the high-acid load diet group only, we found a positive association between the change in dietary PRAL and both the change in CTX and osteocalcin (i.e. the higher the acid load the greater the increase in bone turnover markers), indicating a potential influence of dietary acid-base balance on bone turnover on a more Western dietary pattern. Apart from the potential beneficial reduction in urinary $\mathrm{Ca}$ excretion, we could not demonstrate any other beneficial effects on bone turnover with the low-Na, low-acid load dietary pattern. The LNAB diet resulted in a significant decrease in urinary $\mathrm{Na}$ and a greater reduction in urinary $\mathrm{Ca}$ excretion, with $\mathrm{Ca}$ 
excretion decreasing by $16 \mathrm{mg} / 40 \mathrm{mmol} \mathrm{Na}$ reduction. This result is comparable with other published reports which have demonstrated that a reduction in $\mathrm{Na}$ intake reduces urinary $\mathrm{Ca}$ losses ${ }^{(11,35)}$ and may have a long-term beneficial effect by reducing bone loss ${ }^{(12)}$.

Subjects appeared to comply well with the dietary recommendations as evidenced by the assessment of food group diaries and confirmed by results from the repeat $24 \mathrm{~h}$ food records. For dietary $\mathrm{K}$ there was a clear increase in reported intake in the LNAB diet of $1106 \mathrm{mg} / \mathrm{d}(28 \mathrm{mmol} / \mathrm{d})$, but the increase in urinary $\mathrm{K}$ excretion was modest at only $6 \mathrm{mmol} / \mathrm{d}$. Although the difference in the change between groups was only marginally significant, we do believe there was a real difference in dietary $\mathrm{K}$ intake. We have previously found that at higher intakes of dietary $\mathrm{K}$, urinary $\mathrm{K}$ does not accurately reflect dietary intake ${ }^{(36)}$.

\section{Limitations of the study}

The benefit of using biochemical markers is that they are non-invasive and produce results in a short timeframe ${ }^{(37)}$. Although the present study was relatively short (14 weeks), we expected to detect effects on bone turnover, as bisphosphates have a clear effect on bone resorption at $7 \mathrm{~d}$, and changes in bone formation are seen by 2 months ${ }^{(38)}$, and Lin et al. found significant differences in bone after $30 \mathrm{~d}$ dietary intervention $^{(13)}$. It is possible that a longer study may capture the full extent of bone formation changes, as markers of bone formation can lag behind changes in markers of bone resorption $^{(39)}$. We acknowledge that we only had limited power to detect difference in bone turnover markers, due to the wide variability. Based on post-study calculations, we had $80 \%$ power to detect an 11-18\% difference in serum CTX, but only between $50-80 \%$ power to detect an $11 \%$ difference in PINP at $P<0.05$. As with other studies, we found a wide intra-individual variability of the circulating levels of bone turnover markers ${ }^{(40-42)}$, and it is possible that there were small changes in bone turnover that were below detectable levels. The menopausal status of subjects may be one of the factors contributing to a wide variability of bone turnover markers; however, there is significant overlap beween early and late menopausal status for markers of bone turnover, suggesting that this is an unlikely factor ${ }^{(40,43)}$. Seasonal variation may also have contributed to high variability in bone turnover markers; however, this too is unlikely, as there was no difference in serum 25-hydroxyvitamin D levels during the study for either group. Food intake and circadian variability seems to have strong effects on bone resorption and although we minimised these effects by taking measurements after an overnight fast, these factors may have contributed to the high variability.

Overall, bone resorption was not different between the LNAB and HCLF diets. The dietary acid load did not have a consistent effect on bone turnover and the biological significance of the changes in bone turnover, particulary the increase in PINP, a bone formation marker, with the higher-acid load diet in the present short-term study is not clear. The fall in urinary $\mathrm{Ca}$ excretion on the lower-Na DASH-type diet is likely to have a beneficial effect on bone in the long term. This reduction in urinary $\mathrm{Ca}$ was driven by the reduction in dietary $\mathrm{Na}$, but longer-term studies are required to confirm the benefits of this type of dietary pattern. It would be worthwhile to assess if a lower-acid load diet assists in maintaining bone health on a lower-Ca diet, as this is particularly relevant for older individuals who usually find it difficult to consume sufficient dietary $\mathrm{Ca}$ from food sources.

\section{Acknowledgements}

The present study was supported by Meat \& Livestock Australia. We thank Dr Mark Devlin for assisting in reviewing the literature and initial manuscript drafting.

The authors' responsibilities were as follows: C. A. N. was responsible for the study concept, design, interpretation of data and critical revision of the manuscript for important intellectual content; A. P. was responsible for the collection of data; N. W. was responsible for the analysis and interpretation of data and writing of the manuscript.

The authors had no financial or personal conflict of interest.

\section{References}

1. MacInnis RJ, Cassar C, Nowson CA, et al. (2003) Determinants of bone density in 30- to 65-year-old women: a co-twin study. $J$ Bone Miner Res 18, 1650-1656.

2. Kalkwarf HJ, Khoury JC \& Lanphear BP (2003) Milk intake during childhood and adolescence, adult bone density, and osteoporotic fractures in US women. Am J Clin Nutr 77, 257-265.

3. Sebastian A, Frassetto LA, Sellmeyer DE, et al. (2002) Estimation of the net acid load of the diet of ancestral preagricultural Homo sapiens and their hominid ancestors. Am J Clin Nutr 76, 1308-1316.

4. Lanham-New SA (2008) The balance of bone health: tipping the scales in favor of potassium-rich, bicarbonate-rich foods. $J$ Nutr 138, 172S-177S.

5. Wynn E, Lanham-New SA, Krieg MA, et al. (2008) Low estimates of dietary acid load are positively associated with bone ultrasound in women older than 75 years of age with a lifetime fracture. J Nutr 138, 1349-1354.

6. Macdonald HM, New SA, Fraser WD, et al. (2005) Low dietary potassium intakes and high dietary estimates of net endogenous acid production are associated with low bone mineral density in premenopausal women and increased markers of bone resorption in postmenopausal women. Am J Clin Nutr 81, 923-933.

7. Prynne CJ, Mishra GD, O'Connell MA, et al. (2006) Fruit and vegetable intakes and bone mineral status: a cross sectional study in 5 age and sex cohorts. Am J Clin Nutr 83, 1420-1428.

8. Tucker KL, Hannan MT, Chen H, et al. (1999) Potassium, magnesium, and fruit and vegetable intakes are associated with greater bone mineral density in elderly men and women. $A m$ J Clin Nutr 69, 727-736.

9. Rafferty K, Davies KM \& Heaney RP (2005) Potassium intake and the calcium economy. J Am Coll Nutr 24, 99-106.

10. Carbone LD, Bush AJ, Barrow KD, et al. (2003) The relationship of sodium intake to calcium and sodium excretion and bone mineral density of the hip in postmenopausal African-American and Caucasian women. $J$ Bone Miner Metab 21, 415-420.

11. Nordin BEC, Need AG, Morris HA, et al. (1993) The nature and significance of the relationship between urinary sodium and urinary calcium in women. $J$ Nutr 123, 1615-1622. 
12. Devine A, Criddle R, Dick I, et al. (1995) A longitudinal study of the effect of sodium and calcium intakes on regional bone density in postmenopausal women. Am J Clin Nutr 62, 740-745.

13. Lin P-H, Ginty F, Appel LJ, et al. (2003) The DASH diet and sodium reduction improve markers of bone turnover and calcium metabolism in adults. $J$ Nutr 133, 3130-3136.

14. Hannan MT, Tucker KL, Dawson-Hughes B, et al. (2000) Effect of dietary protein on bone loss in elderly men and women: The Framingham Osteoporosis Study. J Bone Miner Res 15, 2504-2512.

15. Sellmeyer DE, Stone KL, Sebastian A, et al. (2001) A high ratio of dietary animal to vegetable protein increases the rate of bone loss and the risk of fracture in postmenopausal women. Am J Clin Nutr 73, 118-122.

16. Munger RG, Cerhan JR \& Chiu BC-H (1999) Prospective study of dietary protein intake and risk of hip fracture in postmenopausal women. Am J Clin Nutr 69, 147-152.

17. Nowson CA, Wattanapenpaiboon N \& Patchett A (2007) Effect of a low sodium, base producing diet on blood pressure in postmenopausal women. Ann Nutr Metab 51, Suppl. 1, 263, Abstr.

18. Chobanian AV, Bakris GL, Black HR, et al. (2003) Seventh report of the Joint National Committee on Prevention, Detection, Evaluation, and Treatment of High Blood Pressure. Hypertension 42, 1206-1252.

19. Remer $T$ \& Manz F (1995) Potential renal acid load of foods and its influence on urine pH. J Am Diet Assoc 95, 791-797.

20. Frassetto LA, Lanham-New SA, Macdonald HM, et al. (2007) Standardizing terminology for estimating the diet-dependent net acid load to the metabolic system. J Nutr 137, 1491-1492.

21. Remer T, Dimitriou T \& Manz F (2003) Dietary potential renal acid load and renal net acid excretion in healthy, free-living children and adolescents. Am J Clin Nutr 77, 1255-1260.

22. Sacks FM, Svetkey LP, Vollmer WM, et al. (2001) Effects on blood pressure of reduced dietary sodium and the Dietary Approaches to Stop Hypertension (DASH) diet. DASH-Sodium Collaborative Research Group. N Engl J Med 344, 3-10.

23. Buclin T, Cosma M, Appenzeller M, et al. (2001) Diet acids and alkalis influence calcium retention in bone. Osteoporos Int $\mathbf{1 2}$, 493-499.

24. Bushinsky DA (2001) Acid-base imbalance and the skeleton. Eur J Nutr 40, 238-244.

25. Reginster J-Y, Henrotin Y, Christiansen C, et al. (2001) Bone resorption in post-menopausal women with normal and low BMD assessed with biochemical markers specific for telopeptide derived degradation products of collagen type I. Calcif Tiss Int 69, 130-137.

26. Barzel US \& Jowsey J (1969) The effects of chronic acid and alkali administration on bone turnover in adult rats. Clin Sci 36, 517-524

27. Lemann J Jr, Litzow JR \& Lennon EJ (1966) The effects of chronic acid loads in normal man: further evidence for the participation of bone mineral in the defense against chronic metabolic acidosis. J Clin Invest 45, 1608-1614.
28. Arnett TR \& Spowage M (1996) Modulation of the resorptive activity of rat osteoclasts by small changes in extracellular $\mathrm{pH}$ near the physiological range. Bone 18, 277-279.

29. Kristensen M, Jensen M, Kudsk J, et al. (2005) Short-term effects on bone turnover of replacing milk with cola beverages: a 10-day interventional study in young men. Osteoporos Int 16, $1803-1808$.

30. Hampson G, Martin FC, Moffat K, et al. (2003) Effects of dietary improvement on bone metabolism in elderly underweight women with osteoporosis: a randomised controlled trial. Osteoporos Int 14, 750-756.

31. Deal C, Omizo M, Schwartz EN, et al. (2005) Combination teriparatide and raloxifene therapy for postmenopausal osteoporosis: results from a 6-month double-blind placebo-controlled trial. J Bone Miner Res 20, 1905-1911.

32. Peris P, Alvarez L, Monegal A, et al. (1999) Biochemical markers of bone turnover after surgical menopause and hormone replacement therapy. Bone 25, 349-353.

33. Mostaza JM, De la Piedra C, Díaz Curiel M, et al. (2001) Pravastatin therapy increases procollagen I N-terminal propeptide (PINP), a marker of bone formation in post-menopausal women. Clin Chim Acta 308, 133-137.

34. Macdonald HM, Black AJ, Aucott L, et al. (2008) Effect of potassium citrate supplementation or increased fruit and vegetable intake on bone metabolism in healthy postmenopausal women: a randomized controlled trial. Am J Clin Nutr 88, $465-474$.

35. Need AG, Morris HA, Cleghorn DB, et al. (1991) Effect of salt restriction on urine hydroxyproline excretion in postmenopausal women. Arch Intern Med 151, 757-759.

36. Nowson CA, Worsley A, Margerison C, et al. (2004) Blood pressure response to dietary modifications in free-living individuals. $J$ Nutr 134, 2322-2329.

37. Seibel MJ (2006) Biochemical markers of bone turnover part II: clinical applications in the management of osteoporosis. Clin Biochem Rev 27, 123-138.

38. Sebba A, Broy S, Kohles JD, et al. (2008) Rapid suppression of bone resorption marker levels with ibandronate therapy in a bisphosphonate-naive population. J Clin Densitom 11, 417-423.

39. Watts NB (1999) Clinical utility of biochemical markers of bone remodeling. Clin Chem 45, 1359-1368.

40. Hannon H \& Eastell R (2000) Preanalytical variability of biochemical markers of bone turnover. Osteoporos Int 11, S30-S44.

41. Scariano JK, Garry PJ, Montoya GD, et al. (2002) Diagnostic efficacy of serum cross-linked N-telopeptide (NTx) and aminoterminal procollagen extension propeptide (PINP) measurements for identifying elderly women with decreased bone mineral density. Scand J Clin Lab Invest 62, 237-243.

42. Vesper HW (2005) Analytical and preanalytical issues in measurement of biochemical bone markers. Lab Med 36, 424-429.

43. Garnero P, Sornay-Rendu E, Chapuy MC, et al. (1996) Increased bone turnover in late postmenopausal women is a major determinant of osteoporosis. J Bone Miner Res 11, 337-349. 